\title{
MANAGING SPORTS: EXPLORING INNOVATIVE STRATEGIES AND FUTURE ADVANCEMENTS
}

\author{
Tasleem Arif ${ }^{1 *}$, Sohail Roman ${ }^{2}$, Mehreen Saba ${ }^{3}$, and Imdad Ali ${ }^{4}$
}

\begin{abstract}
The current study is focused on understanding the mass media impact of the promotion of sport management in Pakistan, especially in the province of Khyber Pakhtunkhwa and uncovering innovative promotional approaches. For data collection, a quantitative research method with a cross-sectional survey design was used. For survey instrumentation, a close-ended questionnaire was adopted and disseminated to the target population. A total of 600 participants' pool was contacted which comprised of sportsmen, media representatives and other officials in KP-Pakistan with an age range of 14 years and above. A convenient sampling approach was employed to examine the role of mass media in the promotion of sports management. The findings revealed that the influence of mass media in the promotion of sports regarding public attitudes have a strong positive role, and media is significantly disseminating information about the value of sports participation and its role in promoting sports culture. It is observed and validated that the mass media plays a significant role in the promotion of sports in KP. Thus, in this study, the potential of mass media to influence and raise public awareness in sports promotion has been highlighted. Sports massively attracts the attention of both print and electronic media; therefore, it is suggested to gain the public interest and generate revenue at large from the sports industry.
\end{abstract}

Keywords: Sports Management; Sports Innovation; Mass Media; Social Influence; Cross-Sectional Study.

\section{INTRODUCTION}

Media and sport are two distinct societal institutions which are inextricably linked (Cooper et al., 2019; Rowe, 2003). Sport is a sphere of live action and entertainment, whereas media is a

\footnotetext{
${ }^{1}$ Assistant Professor, Sports Science \& Physical Education, The University of Haripur, Haripur-Pakistan. Email: tasleem.arif@uoh.edu.pk

${ }^{2}$ Lecturer, DSS\&PE, Sarhad University of Science \& Information Technology, Peshawar-Pakistan.

${ }^{3}$ Lecturer, DSS\&PE, Bahauddin Zakriya University, Multan-Pakistan.

${ }^{4}$ Master Candidate, DSS\&PE, Sarhad University of Science \& Information Technology, Peshawar-Pakistan.

*Corresponding Author
} 
medium that allows the live action to reach the public in both nearby and distant regions (Marwat et al., 2014). The attention of mass media such as newspapers, magazines, radio, television, and, more recently, the Internet and their extensive sport coverage is a function of increasing interest in sport among the general public. The leadership and guidance role of the media is the second most important responsibility of the media (Shank \& Lyberger, 2014). Mobile phone users rapidly increase in the contemporary age, while social media has impacted the perceptions over participation in sports (Abeza et al., 2015). Individuals utilize social media applications like Facebook, Twitter, Instagram, and YouTube on a regular basis in order to develop some sort of understanding towards a specific area like training, exercise and physical activity interventions (Arora et al., 2019; Reuter, \& Spielhofer, 2017). Social media has expanded its importance in order to sharing material, drawing new readers, and encouraging involvement. Social media platforms have affected sports behavior and participations with a number of ways, including communications and sports marketing (Achen, 2017; Billings et al., 2017). Currently, sports and media have a close association due to an increasing number of scholars and professionals' especially sports marketing and consumer behavior (Nam-Ik Kim \& Sun-Mun Park, 2017).

Communities, by and large, contend with with the phenomenon of sport and mass media, which leads to a symbiotic relationship with sports participants and management (Goldlust, 2018). The audience interests in sports draw the attention of mass media (newspapers, magazines, radio, television, and social media) in order to cover the wide range of sports activities (Nazari, \& Ghasemi, 2011; Boyle, 2009). Sports marketing is a branch of marketing that focuses on both the promotion of sporting events and teams, as well as the promotion of other products and services via sporting events and teams. It is a service that promotes a physical product or a brand name (Giroux, Pons \& Maltese, 2017).

Media is considered as the most influential and comprehensive mode of communication (Jensen, 2020; Van Dijk, 2020). The most common modes of communication are mass media including print (newspapers, journals, and magazines), or electronic transmission (Television and radio) and social media (Facebook, YouTube, Twitter, and Instagram) (Grossberg et al., 2006). Broad media platforms provide the access for sports coverage to the wider range of masses (Ke Ren, 2017).

The media plays an important role in sport promotion and in terms of generating revenue by providing free publicity and advertisements (Shilbury et al., 2020; Katz, 2016). Mass media plays a critical role in producing, reproducing, and amplifying the issues associated with sports like coverage, management, and publicity (Shilbury et al., 2020). 


\section{LITERATURE REVIEW}

\section{Mass Media Communication}

Mass communication refers to the process of disseminating and transferring information to broad portions of the public through mass media (Aggarwal, \& Gupta, 2001). It is widely used to refer to many types of media, as its technologies are employed for information distribution, such as journalism and advertising. Mass communication varies from other forms of communication in that it concentrates on specific resources while simultaneously conveying information to a vast number of receivers (Turow, 2013). Mass communication research focuses on how the content of mass communication impacts or persuades behavior, attitude, opinion, or emotion (Sanborn, \& Harris, 2019).

\section{Types of Communication Modes}

The communication modes include three broad types: print, electronic and social media. All these three modes have their own unique characteristics. Print media include newspapers (local, national, daily), weekly magazines biographies, novels and journals. Electronic media comprises of television broadcasts, cell phone communication, and communication through computer (laptops, tablets) and radio. Similarly, the social media communication is conducted through Whatsapp, Twitter, Tiktok, Likee, Snack Video, YouTube, Facebook, WeChat, Instagram and other similar channels.

\section{Sports}

Sport is any competitive physical activity or game that seeks to utilize, maintain, or enhance physical ability and skills, giving enjoyment, entertainment to participants and spectators (Woods, \& Butler, 2020; Sterchele, 2015). Sports, whether recreational or structured, have the potential to enhance one's physical health and improve the standard of fitness (Møller et al., 2014; Lower et al., 2013; Downward, \& Rasciute, 2010). Many competitors participate continuously or sequentially in certain sports, such as racing, with one winner; in others, the contest (a match) is between two sides, each striving to exceed the other. Some sports allow for a "tie" or "draw," in which no single winner is established; others include tie-breaking mechanisms to ensure that one winner and one loser are selected (Connolly, \& White, 2017; Fu et al., 2015). A tournament can be made up of several competitions that end in the crowning of a champion (Moosavian, \& Roodsari, 2014; Borowy, 2013). Many sports leagues choose an annual champion by scheduling games throughout the regular sports season, followed by playoffs in certain circumstances (Durán, 2021; Lenten, 2016).

\section{Role of Media in the Development of Sports Activities}


Media activities in sport are carried out to convey and send messages to the audience from sport organizations, associations, federations, departments or directorate (Pedersen et al., 2020; Boyle, \& Haynes, 2014). Moreover, the messages consist upon sharing knowledge, skills, attitudes, and information, which leads to develop some sort of specific aptitude and behavior of the concern masses. Presently, online media considered in sport as a powerful tool which has been established among the mass media (Geurin, 2017; Creeber, \& Martin, 2008).

\section{Impact of Media on Sports}

Populations are aware about the media impact on sports whether they participate or watch (Thomas et al., 2018). Sports from the local, national, and international levels are all represented. From school sport newsletters to worldwide TV coverage, the media has a significant impact on sport (Owens, 2021; Shilbury et al., 2020). Aside from paying for the rights to show a sports event, the media may impact sport's appeal, give free advertising for local teams, feature player personalities, and create fan devotion to teams and individual players (Mullin et al., 2014; Rowe, \& Gilmour, 2010). Mass media positively impacts on sports in order to develop and highlight many of the potential aspects such as Increase sport's visibility, encourage people to live healthy, active lifestyles, showcase positive and motivating role model, encourage folks to participate, set high performance goals and provide examples of skills and techniques, make a variety of sports and activities, increase the popularity of specific sports and to introduce new fans to the sport (Pangrazi, \& Beighle, 2019; Andrew et al., 2019; Jones, 2017; Nabi, \& Oliver, 2009).

\section{OBJECTIVES OF THE STUDY}

1. To assess the role of mass media in sports management at KP.

2. To highlight the relationship of mass media and public attitudes in the promotion of sports management.

\section{HYPOTHESIS OF THE STUDY}

$\mathrm{H}_{A}$ 1: There is significant role of mass media in sports management at KP.

$\boldsymbol{H}_{A}$ 2: There is a positive relationship of mass media and public attitudes in the promotion of sports management.

$\boldsymbol{H}_{A}$ 3: There is significant effect of different mass media in the interest of public's opinion towards sports program. 


\section{METHODS AND MATERIALS}

\section{Research Design}

Keeping in view the nature of the study, a quantitative research method with cross-sectional survey design was used for collecting needed information.

\section{Population}

The population for this study comprised of sportsmen, media representatives and officials in KP-Pakistan. Ages of eighteen (18) years and above, both the genders (Male \& Female) were selected for the collection of data.

\section{Sampling and Sample Size}

The researchers selected a convenient sampling technique to analyze the impact of mass media in the promotion of sports management. For that purpose, 600 participants were selected as a sample from the field of Sports, Media \& officials. Data were collected through closed ended questionnaire. Likert type questionnaire (Strongly Disagree, Disagree, undecided, Agree, and Strongly Agree), which is one of the most popular types of a questionnaire and is usually used for developing the measurement. The preliminary draft of the questionnaire was developed under the supervision of the supervisor in the selected areas (in the light of the literature) to meet the set objectives of this study. The preliminary draft was distributed between 15 experts in the field for validation. Further the questionnaire was divided in to 4 different categories i.e., demographic attributes (Gender, Age, Profession), the second section consisted of 28 statements. The first section/category consists of nine questions about the media and sports involvement. The second segment/category comprised nine questions of about how the media effects public perceptions of sports. Six questions of about how the media influences sports promotion were included in the third segment/category. The last and fourth segment/category include four questions which coved all of them were related to the research of various mass media in the interest of public opinion on sports programs. The method of reliability for internal consistency was applied to evaluate the reliability of the questionnaire. The basic objective of the study is to pre-test the research tool in terms of practicability and feasibility. During the pilot study procedure, the first draft is administered to 19 samples to examine the difficulty level, content, and an ambiguity aspect of the research instrument. Valuable feedback was received from the pilot sample which provided too much help in refining the instrument. Cronbach's alpha was used for the purpose to measure the internal consistency of the items. The Cronbach's alpha value was .779. 


\section{Data Analysis}

To meet the objectives of the current study and with intention of testing hypotheses, data collected were analyzed by using descriptive (frequencies and percentages) and inferential methods (Correlation, Linear Regression and ANOVA) using the Statistical Packages for Social Sciences (Version 25), and MS Excel. Endnote (x9 version) was used for the references.

\section{RESULTS}

Figure 1 below shows the gender wise respondents (male \& female), in which two bar columns were highlighted with colors, first one i.e., blue bar shows male frequency and percentage while red bar shows female frequency and percentage. According to table, $62.2 \%$ of male while $37.8 \%$ of females participated in the study.

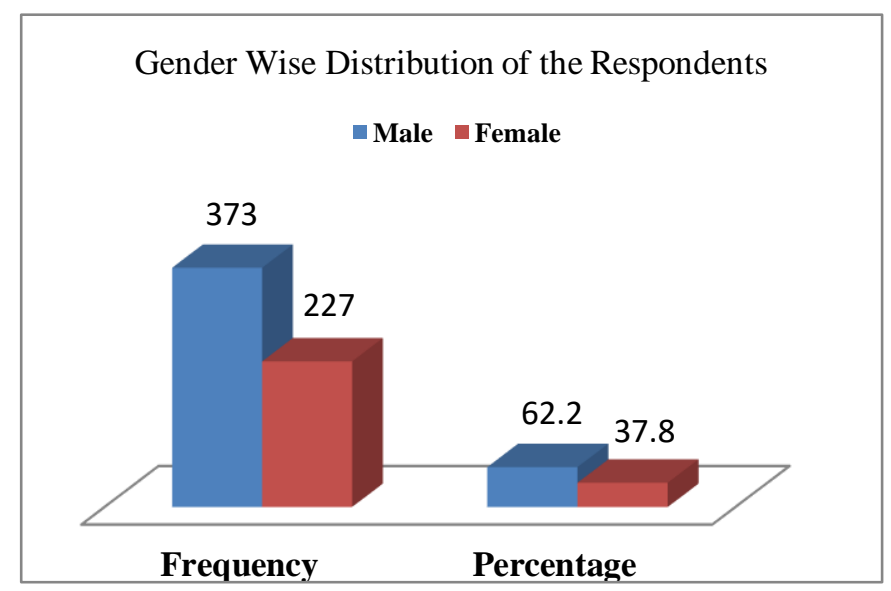

Figure 1. Gender wise Distribution of the Respondents

Figure 2 shows the age wise distribution of the respondents. Results indicate that age wise the responses ratio of participants from 18 to 24 years age bracket was $32 \%, 33.83 \%$ from 25 to 30 years, $20.16 \%$ from $30-36$ years and $14 \%$ from the respondents who belonged to the age bracket of above 37 years, respectively.

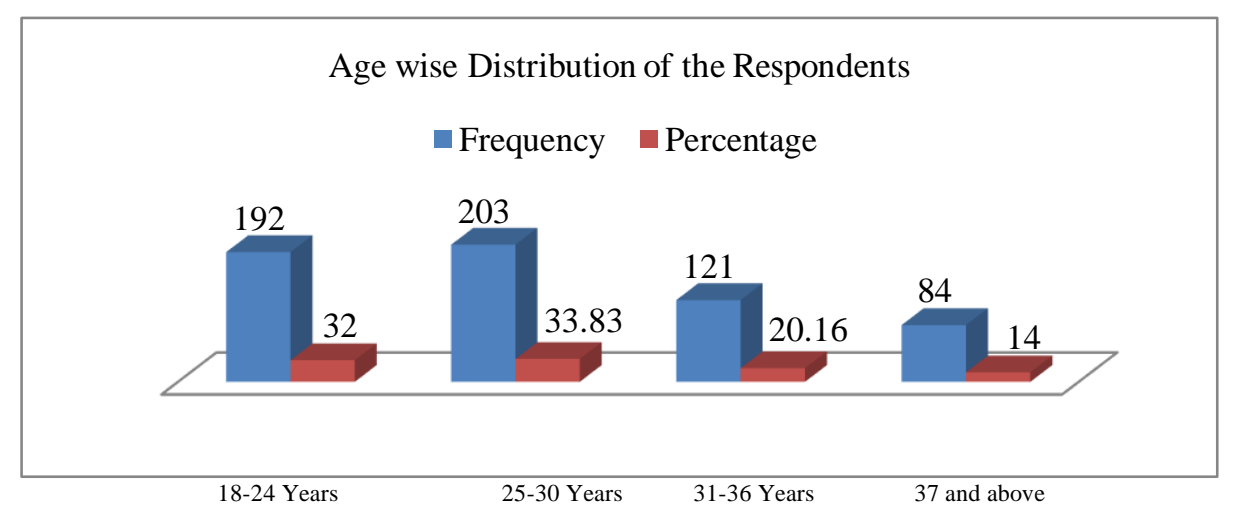

Figure 2. Age wise Distribution of the Respondents 


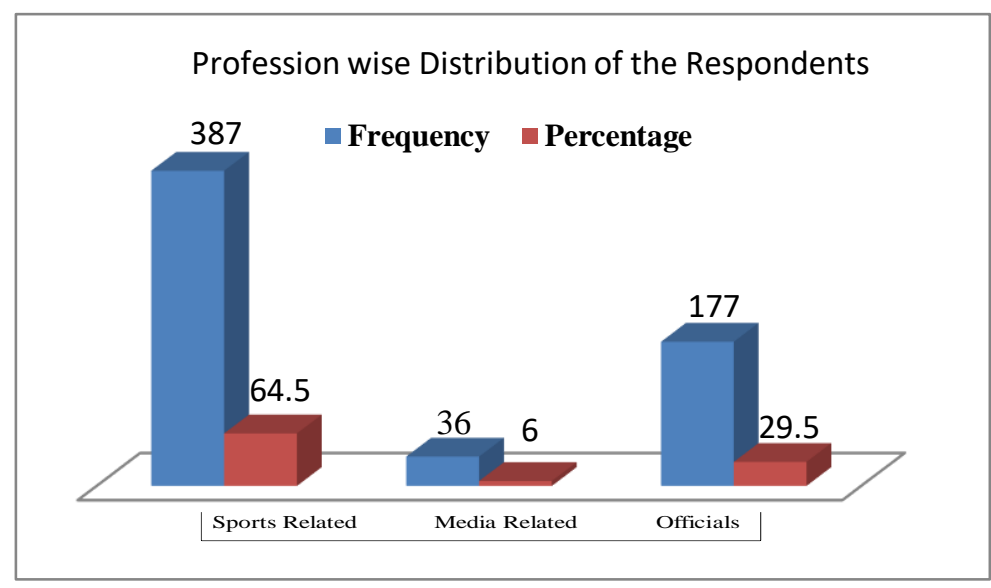

Figure3. Profession wise Distribution of the Respondents

The figure 3 highlights profession wise responded, in which 387 (64.5\%) responded from sports related participants while $36(6 \%)$ from media representatives and rest of (177 participants \& $29.5 \%$ ) were from officials.

\section{Hypothesis Testing}

Table 1. $\mathrm{H}_{\mathrm{A}} 1$ : There is significant role of the mass media in the promotion of sports in KP.

\begin{tabular}{cccc}
\hline Independent variable & $\mathbf{N}$ & $\mathbf{r}$ & Sig \\
\hline Mass Media & 600 & $.769^{* *}$ & $\mathbf{0 0 0}$ \\
\hline
\end{tabular}

The table 1 shows the role of the mass media in the sports promotion. The relationship between the role of the mass media and sports promotion is positive $(r=.769)$ and statistically significant $(\mathrm{p}=.000 .05)$. As a result, the research hypothesis states that the mass media plays a significant role in the promotion of sports in KP.

Table 2. $\mathrm{H}_{\mathrm{A}} 2$ : There is a significant influence of mass media in the promotion of sports regarding public attitudes.

\begin{tabular}{cccccccc}
\hline $\mathbf{R}$ & $\mathbf{R}^{2}$ & Adj $\mathbf{R}^{2}$ & $\mathbf{B}$ & $\mathbf{F}$ & $\mathbf{t}$ & Sig & Durbin-Watson \\
\hline 0.761 & 0.579 & 0.577 & 0.098 & 457.17 & 323 & 0.003 & 1.545 \\
\hline
\end{tabular}

$a=0.05 \& D . W=1.5$ to 2.5

Results of table 2 show the regression output indicates that there is a significant influence of mass media in the promotion of sports regarding public attitudes, because statically proved from the above results that is less than to the sigma level, $\mathrm{P}=0.003<0.05$. The result indicates that $\mathrm{R}=0.761$ regarding public attitudes that mass media influence is $76 \%$ in the promotion of sports. The $\boldsymbol{\beta}$ value indicates that one-unit increase in mass media then 0.098 unit will increase in the promotion of sports. The autocorrelation issue in the data was addressed using the Durbin 
Watson test. The table shows that Durbin Watson's value i.e., 1.545 is within acceptable range. As a result, there is no issue with autocorrelation in the data that meets the regression assumption.

Table 3. Different Mass Media - wise variances (ANOVA)

\begin{tabular}{llcccccc}
\hline Variables & Designation & N & Mean & Std. & df & F & Sig. \\
\hline \multirow{4}{*}{ Different Mass Media } & TV & 241 & 4.5831 & .23450 & & & \\
& Social Media & 131 & 3.8525 & .12720 & & & \\
& Internet & 117 & 3.6091 & .09679 & 596 & 274.442 & 0.000 \\
& Newspaper & 22 & 2.2107 & .04644 & & & \\
& Radio & 89 & 2.5787 & .03809 & & & \\
\hline
\end{tabular}

$a=0.05$

$\mathrm{H}_{\mathrm{A}}$ 3: There is significant effect of different mass media in the interest of public's opinion towards sports program.

Table 3 displays the results of the ANOVA analysis and whether or not there is a statistically significant difference between the means of the various groups. The significance value for various groups of different mass media are shown in this table 0.000 which are below 0.05 . and, therefore, there is a statistically significant difference in the mean of respondents in different mass media in the interest of public's opinion towards sports program.

\section{DISCUSSION AND CONCLUSION}

\section{Discussion}

The findings show that the media has a strong ability to influence and raise public awareness in the context of sports. The findings of the study show that sport participation is increasing every day. This study included $600 \mathrm{KP}$ (Pakistan) participants from the sports, other, and media fields, with 62.2 percent males and $37.8 \%$ females. The majority of respondents were between the ages of 26-35 (33.83\%) and working in a sports field (64.5\%), with 14.66\% of those over 46 years old. According to the findings, the media has a strong ability to influence and raise public awareness in sports culture. The results show of this study that the mass media plays a significant role in the promotion of sports in KP. According to the findings, media has a strong ability to influence and raise public awareness about sports culture (Heikkilä, Lauronen, \& Purhonen, 2018; Bail, 2016; Thorpe, 2008). The participants in this study demonstrate that the media should pay attention to all aspects of sports by raising awareness of the importance of physical activity for good health. Moreover, national projects to promote and encourage sport promotion are embraced by the media (Dai, \& Menhas, 2020; Hays et al., 2013; Hambrick, \& Svensson, 2015). This study found the significant influence of mass media in the promotion of sports regarding public attitudes and media has an impact on current sports culture (Deans et 
al., 2017; Funk, \& Filo, 2013; Moscoso et al., 2018; Kiania, \& Rezvandib, 2021) . This study revealed that mass media in the interest of public's opinion towards sports program (Pilar et al., 2019; Belloni, 2014; Kolotouchkina et al., 2021). In addition, mass media (TV, newspapers, and social media) play an important role in the development of sports infrastructure and public interest in sports participation (Trivedi, Soni, \& Kishore, 2020; Thorpe, 2017; Shilbury et al., 2020; Tamir et al., 2015). The current study suggested that media pays attention to various aspects of sport, such as equipment and facilities, scientific research, talent identification, athlete-related issues, instructor-related issues, sponsorship, public sports, and management and planning, all of which contribute to the sport's growth and promotion.

\section{Conclusion}

The current study examined the impact of mass media in the promotion of sport management. The mass media plays a significant role in the promotion of sports in KP. The ability of mass media to influence and raise public awareness in sport promotion has been highlighted. In addition, the results show an increase in sport participation. Moreover, the media is disseminating information about the value of sports participation and its role in promoting sports culture. People are informed and entertained by media in all of its forms. The media share the interesting and relevant news stories, which could draw the viewer's attention. This study concluded that influence of mass media in the promotion of sports regarding public attitudes have strong positive role. The researcher also seen that there is significant difference in the mean of respondents in different mass media in the interest of public's opinion towards sports program. The researchers also looked at how the media affects sport promotion, from free publicity for teams and athletes to how they influence the popularity of specific sports or all sports. Sport has attracted the attention of both print and electronic media; therefore, it is suggested to gain the public interest and generate the revenue at large.

\section{STUDY IMPLICATIONS}

This study will be helpful and beneficial for policy makers and sports administrators in order to develop their policies and strategies for different stakeholders. These stakeholders such as athletes/players, officials, and media persons (sports journalists) are considering the key individuals to highlight the positive, constructive, and attractive aspects of each and every sports event. This study would be helpful in order to generate and collect the huge revenue through the healthy conduct and positive attitudes of public. 


\section{REFERENCES}

Abeza, G., O’Reilly, N., Séguin, B., \& Nzindukiyimana, O. (2015). Social media scholarship in sport management research: A critical review. Journal of Sport Management, 29(6), 601-618.

Achen, R. M. (2017). Measuring social media marketing: Moving towards a relationshipmarketing approach. Managing Sport and Leisure, 22(1), 33-53.

Aggarwal, V. B., \& Gupta, V. S. (2001). Handbook of journalism and mass communication. Concept Publishing Company.

Andrew, D. P., Pedersen, P. M., \& McEvoy, C. D. (2019). Research methods and design in sport management. Human Kinetics

Arora, A., Bansal, S., Kandpal, C., Aswani, R., \& Dwivedi, Y. (2019). Measuring social media influencer index-insights from Facebook, Twitter and Instagram. Journal of Retailing and Consumer Services, 49, 86-101.

Bail, C. A. (2016). Cultural carrying capacity: Organ donation advocacy, discursive framing, and social media engagement. Social Science \& Medicine, 165, 280-288.

Beck, D., \& Bosshart, L. (2003). Sports and Media. Communication Research Trends, Vol 22 No. 4: 03-15.

Belloni, E. (2014). The Birth of the sport nation: sports and mass-media in Fascist Italy. Aloma: Revista de Psicologia, Ciències de l'Educació i de l'Esport, 32(2).

Billings, A. C., Qiao, F., Conlin, L., \& Nie, T. (2017). Permanently desiring the temporary? Snapchat, social media, and the shifting motivations of sports fans. Communication \& Sport, 5(1), 10-26.

Borowy, M. (2013). Pioneering eSport: the experience economy and the marketing of early 1980s arcade gaming contests. International Journal of Communication, 7, 21.

Boyle, R. (2009). Power play: Sport, the media and popular culture: Sport, the media and popular culture. Edinburgh University Press.

Boyle, R., \& Haynes, R. (2014). Sport, public relations and social media.

Connolly, F., \& White, P. (2017). Game changer. Simon and Schuster.

Cooper, J. N., Macaulay, C., \& Rodriguez, S. H. (2019). Race and resistance: A typology of African American sport activism. International Review for the Sociology of Sport, 54(2), 151-181.

Creeber, G., \& Martin, R. (2008). Digital culture: Understanding new media: Understanding new media. McGraw-Hill Education (UK).

Dai, J., \& Menhas, R. (2020). Sustainable development goals, sports and physical activity: the localization of health-related sustainable development goals through sports in China: a narrative review. Risk Management and Healthcare Policy, 13, 1419. 
Deans, E. G., Thomas, S. L., Derevensky, J., \& Daube, M. (2017). The influence of marketing on the sports betting attitudes and consumption behaviours of young men: implications for harm reduction and prevention strategies. Harm Reduction Journal, 14(1), 1-12.

Downward, P., \& Rasciute, S. (2010). The relative demands for sports and leisure in England. European sport management quarterly, 10(2), 189-214.

Durán, G. (2021). Sports scheduling and other topics in sports analytics: a survey with special reference to Latin America. Top, 29(1), 125-155.

Dziubiński, Z., Jankowski, K. W., Lenartowicz, M., Murrmann, J., \& Rymarczyk, P. (2012). Mass media and professional sport. Baltic Journal of Health and Physical Activity, 4(4), 284-294.

Erwin, H. (2016). The use of social media by physical educators: How do we ensure quality control? Journal of Physical Education, Recreation \& Dance, Vol-87:2, 3-14.

Fu, Q., Lu, J., \& Pan, Y. (2015). Team contests with multiple pairwise battles. American Economic Review, 105(7), 2120-40.

Funk, D. C., \& Filo, K. (2013). Sport promotion through communication: A mass media perspective. In Routledge handbook of sport management (pp. 298-312). Routledge.

Geurin, A. N. (2017). Elite female athletes' perceptions of new media use relating to their careers: A qualitative analysis. Journal of Sport Management, 31(4), 345-359.

Giroux, M., Pons, F., \& Maltese, L. (2017). The role of perceived brand personality in promotion effectiveness and brand equity development of professional sports teams. International Journal of Sports Marketing and Sponsorship.

Goldlust, J. (2018). Playing for keeps: Sport, the media and society. Hybrid Publishers.

Grossberg, L., Wartella, E., Whitney, D. C., \& Wise, J. M. (2006). Mediamaking: Mass media in a popular culture. Sage.

Gulam, A. (2016). Role of mass media in sports communication. International Journal of Advanced Educational Research, 5(1), 51-53.

Hambrick, M. E., \& Svensson, P. G. (2015). Gainline Africa: A case study of sport-fordevelopment organizations and the role of organizational relationship building via social media. International Journal of Sport Communication, 8(2), 233-254.

Hays, S., Page, S. J., \& Buhalis, D. (2013). Social media as a destination marketing tool: its use by national tourism organisations. Current issues in Tourism, 16(3), 211-239.

Heikkilä, R., Lauronen, T., \& Purhonen, S. (2018). The crisis of cultural journalism revisited: The space and place of culture in quality European newspapers from 1960 to 2010. European Journal of Cultural Studies, 21(6), 669-686.

Jensen, K. B. (Ed.). (2020). A handbook of media and communication research: Qualitative and quantitative methodologies. Routledge. 
Jones, M. (2017). Sustainable event management: A practical guide. Routledge

Katz, H. (2016). The media handbook: A complete guide to advertising media selection, planning, research, and buying. Routledge.

Kiania, M. S., \& Rezvandib, A. (2021). Examining the relationship between the media and the mass communication in the prosperity of national and international sports events. $J$. Hum. Ins, 5(3), 19-24.

Kim, N. K., \& Park, S. P. (2017). The Relationship between Media Sports Involvement Experiences and Sports Values and Sports Participation. Int. J. Appl. Eng. Res, 12, 9768-9773.

Kolotouchkina, O., Llorente-Barroso, C., García-Guardia, M. L., \& Pavón, J. (2021). Disability, Sport, and Television: Media Visibility and Representation of Paralympic Games in News Programs. Sustainability, 13(1), 256.

Kulbaev, A., Doshybekov, A., Untaev, Z., Nijazakynov, E., \& Lesbekova, R. (2014). Importance of advertising physical education and sport in the media to maintain a healthy lifestyle of nation. World Applied Sciences Journal, 30(4), 438-441.

Kumar, M. (2018). Role of Media in Sports. International Journal of Physiology, Nutrition and Physical Education 3(1): 135-137.

Kumari, H. (2019). Role of media in sports development. International Journal of Physical Education, Sports and Health, 6(1), 97-99.

Lenten, L. J. (2016). Mitigation of perverse incentives in professional sports leagues with reverse-order drafts. Review of Industrial Organization, 49(1), 25-41.

Lower, L. M., Turner, B. A., \& Petersen, J. C. (2013). A comparative analysis of perceived benefits of participation between recreational sport programs. Recreational Sports Journal, 37(1), 66-83.

Marwat, M. K., Waseem, M., Khattak, H., Abbas, A., \& Bi, I. B. (2014). Mass Media and Promotion of Sport (Historical Perspectives). Asian Journal of Social Sciences \& Humanities Vol, 3.

Møller, N. C., Tarp, J., Kamelarczyk, E. F., Brønd, J. C., Klakk, H., \& Wedderkopp, N. (2014). Do extra compulsory physical education lessons mean more physically active childrenfindings from the childhood health, activity, and motor performance school study Denmark (The CHAMPS-study DK). International Journal of Behavioral Nutrition and Physical Activity, 11(1), 1-13.

Moosavian, N., \& Roodsari, B. K. (2014). Soccer league competition algorithm: A novel metaheuristic algorithm for optimal design of water distribution networks. Swarm and Evolutionary Computation, 17, 14-24. 
Moscoso Sanchez, D., Fernandez Gavira, J., \& Perez Flores, A. (2018). The media construction of the sports' elite from the European perspective: An analysis of the European Symposium of Sports 2010. Sport in Society, 21(3), 516-528.

Mullin, B. J., Hardy, S., \& Sutton, W. (2014). Sport marketing 4th edition. Human Kinetics; Nazari, R., \& Ghasemi, H. (2011). The Role of Mass Media on sustainable Sport Development. Revista Pedagógica ADAL, (23), 17-20.

Nabi, R. L., \& Oliver, M. B. (Eds.). (2009). The SAGE handbook of media processes and effects. Sage

Owens, Jim. Television sports production. Routledge, 2021.

Pangrazi, R. P., \& Beighle, A. (2019). Dynamic physical education for elementary school children. Human Kinetics Publishers

Pedersen, P. M., Laucella, P., Geurin, A., \& Kian, E. (2020). Strategic sport communication. Human Kinetics Publishers.

Pilar. P.P, Rafael, C.M., Félix, O. Z \& Gabriel. V. G,. (2019). Role of Mass Media in Sports Promotion. International Journal of Environmental Research and Public Health.16, 486; $1-12$.

Ren, K. (2017). Role of media in the popularization of physique education in higher school. Eurasia Journal of Mathematics, Science and Technology Education, 13(10), 70037008.

Reuter, C., \& Spielhofer, T. (2017). Towards social resilience: A quantitative and qualitative survey on citizens' perception of social media in emergencies in Europe. Technological Forecasting and Social Change, 121, 168-180.

Rowe, D. (2003). Sport, culture \& media: The unruly trinity. McGraw-Hill Education (UK).

Rowe, D., \& Gilmour, C. (2010). Sport, media, and consumption in Asia: A merchandised milieu. American Behavioral Scientist, 53(10), 1530-1548.

Shank, M. D., \& Lyberger, M. R. (2014). Sports marketing: A strategic perspective. Routledge.

Shilbury, D., Westerbeek, H., Quick, S., Funk, D., \& Karg, A. (2020). Strategic sport marketing. Routledge.

Siljak, V, Perovic., A, Parcina, I (2014). Media Influence on the development of the Olympic movement. FIS Communications. UDC, 796:2, 474-478.

Sterchele, D. (2015). De-sportizing physical activity: From sport-for-development to play-fordevelopment. European journal for sport and society, 12(1), 97-120.

Tamir, I., Limor, Y. H., \& Galily, Y. (2015). Sports: Faster, higher, stronger, and public relations. Human Affairs, 25(1), 93-109.

Tavakolli, M., Najafi, A., \& Ramezani, Z. N. (2013). Studying role of mass media in sport development. Advances in Applied Science Research, 4(4), 49-54. 
Thomas, S. L., Bestman, A., Pitt, H., Cassidy, R., McCarthy, S., Nyemcsok, C., ... \& Daube, M. (2018). Young people's awareness of the timing and placement of gambling advertising on traditional and social media platforms: a study of 11-16-year-olds in Australia. Harm Reduction Journal, 15(1), 1-13.

Thorpe, H. (2008). Foucault, technologies of self, and the media: Discourses of femininity in snowboarding culture. Journal of sport and social issues, 32(2), 199-229.

Thorpe, H. (2017). Action sports, social media, and new technologies: Towards a research agenda. Communication \& sport, 5(5), 554-578.

Trivedi, J., Soni, S., \& Kishore, A. (2020). Exploring the Role of Social Media Communications in the Success of Professional Sports Leagues: An Emerging Market Perspective. Journal of Promotion Management, 27(2), 306-331.

Turow, J. (2013). Media today: Mass communication in a converging world. Routledge.

Van Dijk, J. (2020). The network society. Sage.

Woods, R., \& Butler, B. N. (2020). Social issues in sport. Human Kinetics Publishers. 